\title{
THE USE OF DESTRUCTIVE AND NON- DESTRUCTIVE TESTING IN CONCRETE STRENGTH ASSESSMENT FOR A SCHOOL BUILDING
}

\author{
V. Minutolo, S. Di Ronza, C. Eramo, P. Ferla, S. Palladino, R. Zona \\ Engineering Department, University of Campania "L.Vanvitelli", \\ Via Roma 29 - 81031, Aversa (CE), Italy
}

\begin{abstract}
The present paper aims to increase knowledge of the methods of resistance estimating of concrete in situ by means of non-destructive tests used to integrate the quantitative results from cylindrical specimens (core). The results of experimental investigations carried out on concrete conglomerate samples of a school building are shown. The experimental campaign then will be presented like a case study, conducted on a series of concrete beams and pillars of an existing building. The expression obtained through the calibration procedure of the values of non-destructive tests with those provided by the core drills allowed to estimate the average values of the compressive strength of the concrete. It is highlighted how this result was achieved with a very limited core number that are extracted in randomly selected points and that there was a proportionality link with the resistances obtained from non-destructive tests.
\end{abstract}

Keywords: non-destructive testing; concrete structure; Sonreb; ultrasonic testing, rebound index.

Cite this Article: V. Minutolo, S. Di Ronza, C. Eramo, P. Ferla, S. Palladino and R. Zona, The use of Destructive and Non-Destructive Testing in Concrete Strength Assessment for a School Building. International Journal of Advanced Research in Engineering and Technology, 10(6), 2019, pp. 252-267.

http://iaeme.com/Home/issue/IJARET?Volume $=10 \&$ Issue $=6$

\section{INTRODUCTION}

The compressive strength of concrete has a key role in the evaluation of existing buildings in reinforced concrete and it is difficult to estimate on existing structures and after the building process in order to certify the quality of process itself or the level of damage that occurs during the structure life; therefore appropriate procedures of evaluation are required based on structural testing. The most advanced seismic legislations $[1,2]$ have showed interest to the existing buildings indicating that the type, technique and urgency of a possible intervention must be based on a careful evaluation of the structure in question. Therefore, it is needful to define the mechanical characteristics of concrete in situ [3,4,5], and its compressive strength, using not much onerous and invasive tests and methods. Among the methods some indirect testing can 
be used that are based on overall displacement and strain measures after load bearing tests nowadays such testing can be done with very effective and accurate measure of strain and displacement [6]. However direct measure of the material resistance is desirable and especially non-destructive strength estimate. Investigation methods can be destructive and nondestructive; the destructive methods, based on the extraction of concrete samples to be subjected to compression tests, represent the most reliable tool for estimating the mechanical properties of concrete, but they are much invasive. Consequently, only a limited number of samples are generally extracted and the results obtained may not be representative of the overall characteristics of the structure for the estimating the concrete resistance. Non-destructive tests are cheaper but give indirect evaluation hence they are influenced by numerous factors and their results can be unreliable. Masi [7] describes and examines the main non-destructive tests (sclerometric method, ultrasonic method, combined Sonreb method). The solution for assessing the behaviour of existing structures made of reinforced concrete is using of both methods, the destructive (DT) and non-destructive (NDT) methods, and their improvements [8], that allow extending the results obtained with DT surveys at all points. To identify the best correlations between NDT and DT, as seen in [9], the author investigates the properties of concrete by some structural elements extracted from school buildings, designed for vertical loads only. The results of NDT and DT are analysed both on beam elements and on pillar elements. The analysis of the results of the tests carried out in the laboratory show a strong variability of the mechanical characteristics of the concrete for all the structural elements, taken from the same deck, and along the single structural element. Faella et al. [10] make an experimental study on a series of concrete columns with the aim of studying their cyclic behavior under combined horizontal and vertical load. Concrete cores are extracted at different heights for studying both the resistance spatial variability and the influence of the column load history. The formulations available in literature for estimating the concrete strength from cores have provided variable results and not consistent. The application of the combined Sonreb method is shown to be very useful reducing the dispersion of resistance values that can be find from non-destructive tests. Windsor probe test, Schmidt rebound hammer, Ultrasonic Pulse Velocity method, SonReb method [6], Windsor method and a three-parameter combined method, appointed as SonRebWin Method, are utilized in [11] to investigate on the mechanical property of concrete and Ultra Highperformance reinforced concrete [12]. The outputs of these methods are calibrated with the strength of cores extracted from investigated specimens where the non-destructive tests are applied. In the paper, some availability correlation curves $[13,14,15,16]$ are appropriately adapted to the studied concrete. In [17] the authors look at a knowledge-based approach to emergency situations caused by earthquakes or other natural disasters. They illustrate how a multidisciplinary approach enables the integration of technical requirements with those of a historical and cultural nature. The case study presented is the recovery of the ex-city hospital of L'Aquila, in Italy, which was hit by an earthquake in 2009. The integrated use of varying investigation methodologies allows to establish the effectiveness of a knowledge-based approach and generate new ideas for the development of the structure and its strategic role within the city. Concu and Trulli [18] illustrate the results of an experimental test, which intends to check the effectiveness of ultrasonic testing (UT) in detecting anomalies inside concrete elements [19]. For this purpose, UT is carried out on a small concrete wall having different defects deliberately settled inside the wall during casting. The authors show the velocity map on the wall that highlights areas with different values and allows visually detecting areas having particularly low velocity due to the presence of defects. The results since now achieved suggest that velocity maps are powerful tools for concrete defects identification. Therefore, UT data should be first implemented, in order to gather comprehensive information regarding the inside of the concrete element, aiming to locate and size the inner defects. The present paper has been aimed to give suggestions on the use of the methods of concrete resistance estimating in situ by 
means of non-destructive tests in conjunction to quantitative results from destructive test on cylindrical specimens (core). In the following, some techniques evaluating the mechanical properties of concrete in situ will be analyzed. An experimental campaign then will be presented like a case study, conducted on a series of concrete beams and pillars of a school building. The number of destructive and non-destructive tests has been chosen by the management of the building with reference to economic and administrative considerations. In the following the Sonreb tests interpretation has been optimized with respect to the acquired data; it has been shown that despite the few data for destructive tests, the correlation is accurate enough for practical purpose. However, it has been seen that, due to the dispersion of the data caused by heterogeneity of the concrete [20], better results could be obtained by using different correlation for the different storeys. The possibility of such a correlation requires more cores sample for any storey and was not performed due to the data missing. The cubical strength of the concrete was derived from empirical correlations proposed in the literature as a function of the rebound number of the sclerometric test, Ir, and of the propagation speed of ultrasonic waves, V. The correlation formula proposed has been also interpreted taking in account the results on the concrete core tests.

\section{MATERIALS AND METHODS}

Destructive methods represent the most reliable tool for estimating the mechanical properties of concrete, even if they are considerable invasive. For this reason, Italian and European Legislation [21,22] allow reducing the number of destructive tests (and related concrete cores) up to half of those required for the achievement of a given level of knowledge, replacing it with a triple number of non-destructive tests. Non-destructive testing methods analyzed are sclerometric method, ultrasonic method and combined Sonreb method [23,24]. The Sonreb method combines results obtained by the surface hardness with ultrasonic speed.

\subsection{Surface Hardness Method}

All measurements were carried out using a Standard Schmidt Sclerometer setting perpendicular to the faces of the pillars and beams according to the UNI EN 12504-2 [25]. The [25] standard provides on the instructions how performing the sclerometer tests. The instrument consists of a steel beating mass, driven by a mechanical spring, which contrasts a percussion rod on the test surface. The measured rebound height of the mass is related to the surface hardness of the concrete that is an index of its compressive strength. The UNI standard recommends carrying out at least 9 measurements calculating the rebound index as the average of the nine taken readings. The American standard ASTM C 805 [26] recommends, instead, to make of 10 measurements; if one of the measurements differs from the average of seven or more units it is discarded, and a new average is determined based on the other measurements; if more than two measurements differ from the average of seven or more units, they should be discarded. The use of this instrument has among its advantage's simplicity and low cost but it is influenced by humidity conditions, by carbonation, by surface texture, by the orientation of the instrument, by the presence of aggregates in the test area and also it investigates only the surface concrete.

\subsection{Ultrasonic Method}

The ultrasonic method [27], based on the phenomenon of propagation of ultrasonic waves with a variable frequency between $20-120 \mathrm{kHz}$, uses the correlation between the concrete stiffness, through the propagation speed of ultrasonic waves, and its resistance. The test device consists of a mechanical pulse emitter and a receiving device in transparency. The distance between the time of emission and the time of reception of the signal and therefore the wave speed, $\mathrm{V}$, is measured. The analysis is conducted in transparency when the transducers (probes) are aligned, 
while it is in reflection when the probes are placed on the same plane at a distance (L) from each other. The use of ultrasonic method tests allows obtaining, for the concrete, the dynamic modulus of elasticity and the Poisson's number. It is also possible to estimate the concrete resistance in situ as well as to establish its homogeneity within the structure.

\subsection{Sonreb Method}

Several sclerometric and ultrasonic measurements with limited numbers of core samples, allows the combined Sonreb method to be applied to estimate the concrete compressive cubic strength of the beams and pillars. Indeed, the moisture content makes the sclerometric index underestimate and overestimate the ultrasonic speed, and increasing the time, the sclerometric index increases while the ultrasonic speed decreases. Therefore, the combined use of the two tests makes it possible to compensate partially these problems. So, it is possible to use the method in order to get an expression for the concrete in the case study.

The procedure, reported in [5], is based on a few cores extracted in the structures on point where non-destructive sclerometric and ultrasonic measures are done. The cores are subjected to direct compressive tests. An empirical correlation formula is proposed to relate the concrete compressive cubic strength to the non-destructive indexes namely $\mathrm{Ir}$, the rebound index, and V, the ultrasonic speed.

$$
R_{c}=a \times I r^{b} \times V^{c}
$$

The coefficients on the equation (1) have to be determined by the correlation with some destructive tests. As an example, some proposed exponents and coefficients are reported in the literature and summarized in equations (2-5). The obtained expression of $R_{c}$ can be used, in the subsequent indirect testing to obtain the desired concrete resistance whether one does not have sufficient core test results [32].

$$
\begin{aligned}
& R_{C, 1}=7.695 \times 10^{-11} \times I r^{1.4} \times V^{2.6} \\
& R_{c, 2}=1.2 \times 10^{-9} \times I^{1.058} \times V^{2.446} \\
& R_{c, 3}=0.0286 \times I r^{1.246} \times V^{1.85} \\
& R_{c, 4}=9.27 \times 10^{-11} I r^{1.4} \times V^{2.6}
\end{aligned}
$$

It has to be stressed that in equations (2-5) dimensional units affect the results and the coefficients order of magnitude; in particular, $\mathrm{R}_{\mathrm{c}}$ is the compressive cubic strength of equivalent cube in $\mathrm{N} / \mathrm{mm}^{2}$, Ir is the rebound index and V is the ultrasonic speed expressed in $\mathrm{m} / \mathrm{s}$ in expression $(2,3,5)$ while in $\mathrm{km} / \mathrm{s}$ in expression (4).

The relation (2) is proposed by Giacchetti - Menditto [28] while the relation (3) formulated by Pascale - Di Leo [29] is used to estimate the prestressed concrete cubic strength beams of a railway. The relation (4) proposed by Gasparik [30] was taken from tests on concretes of usual composition but is not specified by the author; therefore, it is not well establishing the limits of its applicability. The last equation (5) provided by RILEM NDT4 [31] contains no detailed indications on the limits of its applicability. More detailed description of the framework of NDT and DT procedures can be found in [32] and in [10] with reference to concrete cubic strength assessment.

\subsection{Core Samples}

UNI EN 12390-1 and UNI EN 12504-1 [33,34] recommend to extract concrete core samples with a diameter between 25 and $300 \mathrm{~mm}$ and to use low penetration speed of the core barrel, in order to limit the damage to the sample. According to the UNI EN 12504-1 standard, the core drilling machine must be adequately anchored so that the sample must have a constant diameter 
and a straight axis. The diameter of the cores must be no less than three times the maximum size of the aggregate, while the height must be possibly equal to twice the diameter. After picking up, the cores should be rectified making the faces on which the load will be applied flat and parallel. [35,36].

\section{EXPERIMENTAL TEST}

In this paper, the results of tests on some structural elements (beams and pillars) extracted from a school building are shown. The school building is a modern building with concrete frame structures and with a concrete slab (CelerSap type) thick $20 \mathrm{~cm}$. The building is composed of three blocks, block A, block B and block $C$. The total surface, $S$, is equal to $S=1940 \mathrm{~m}^{2}$; surface block $A, S_{A}$, is equal to $S_{A}=740 \mathrm{~m}^{2}$, surface block $B, S_{B}$, is equal to $S_{B}=1000 \mathrm{~m}^{2}$ and surface block $\mathrm{C}, \mathrm{S}_{\mathrm{C}}$, is equal to $\mathrm{S}_{\mathrm{C}}=200 \mathrm{~m}^{2}$. The building was a new construction just ultimate when it was subjected to the tests. The prescribed resistance of the concrete is C30/37 MPa. The structure was complete of walls, windows and all the finish but was not yet inhabited. The experimental campaign was promoted by the building management, the number of DT and the number of NDT were decided by a compromise between the management, the prescription [1] and literature [3] and it is assumed that the number of DT was $10 \%$ the number of NDT. In particular, the properties of the concrete were investigated on 40 structural elements over two floors: first floor, FF, and basement, BF. A number of 40 non-destructive tests (NDT) were made. In the basement floor 21 tests were carried out, namely 8 on the beams and 13 on the pillars while on the first floor were conducted 19 tests, 8 on the beams and 11 on the pillars. Destructive tests (DT) were carried out on 4 pillars, two at the basement and two at the first floor. The cylindrical core samples were subjected to crushing tests in the laboratory. It was used a concrete rebar locator to determine the location of reinforcement bars within the concrete structures, to identify the points where extracting the cores which performing destructive tests on, no rebar has been cut during specimens' extraction. The tests were divided into several phases: a preliminary, aimed at identifying the points in which to carry out measurements, the second phase necessary for performing non-destructive tests, and the final in which the cores were taken and subjected to compression tests. In summary, they were performed on the entire buildings:

N. 40 surface hardness tests on beams and pillars.

N. 40 ultrasonic tests on beams and pillars.

N. 4 core samples on pillars and its compression tests.

The location of the sclerometric and ultrasonic tests performed on the structures of the basement and of the first floor is shown in Figure 1. The measurement points were choosing randomly, so as to then the results obtained could be representative of the material properties in situ. For each of the 40 measurement points, 10 hammer shots have been used to get the mean value in accordance with the UNI standard [25]. The ultrasonic test was carried out taking care to place a gel between the surface of the conglomerate and the probes. The investigations were performed with the direct method or transparency method. The cores extracted from the pillars at the basement and at the first floor have been marked respectively with $\mathrm{C} 1, \mathrm{C} 2$ and $\mathrm{C} 3, \mathrm{C} 4$. The cores $\mathrm{C} 1$ and $\mathrm{C} 3$ were taken on pillar positioned at the central block $\mathrm{B}$, marked with the number 25 at the basement and at the first floor respectively; the cores belong to the same vertical but are at different storey, hence the result has been aimed to give information on different cast. The cylindrical samples have a diameter of $100 \mathrm{~mm}$. The sampling was performed at the points where non-destructive tests had already been successfully performed, trying to avoid as much as possible the longitudinal and transverse reinforcements. Then the 
samples were treated in the laboratory in order to obtain cylindrical specimens with the height equal to twice the diameter $(\mathrm{h}=200 \mathrm{~mm})$.

No particular surface imperfections neither rebars elements were found due the care in performing the core drilling and as an adequate fixing of the core drilling machine. Subsequently, in the laboratory were carried out compression tests on the cores after their surface grinding. The test was performed with a Tecnotest KC 300 compression machine.

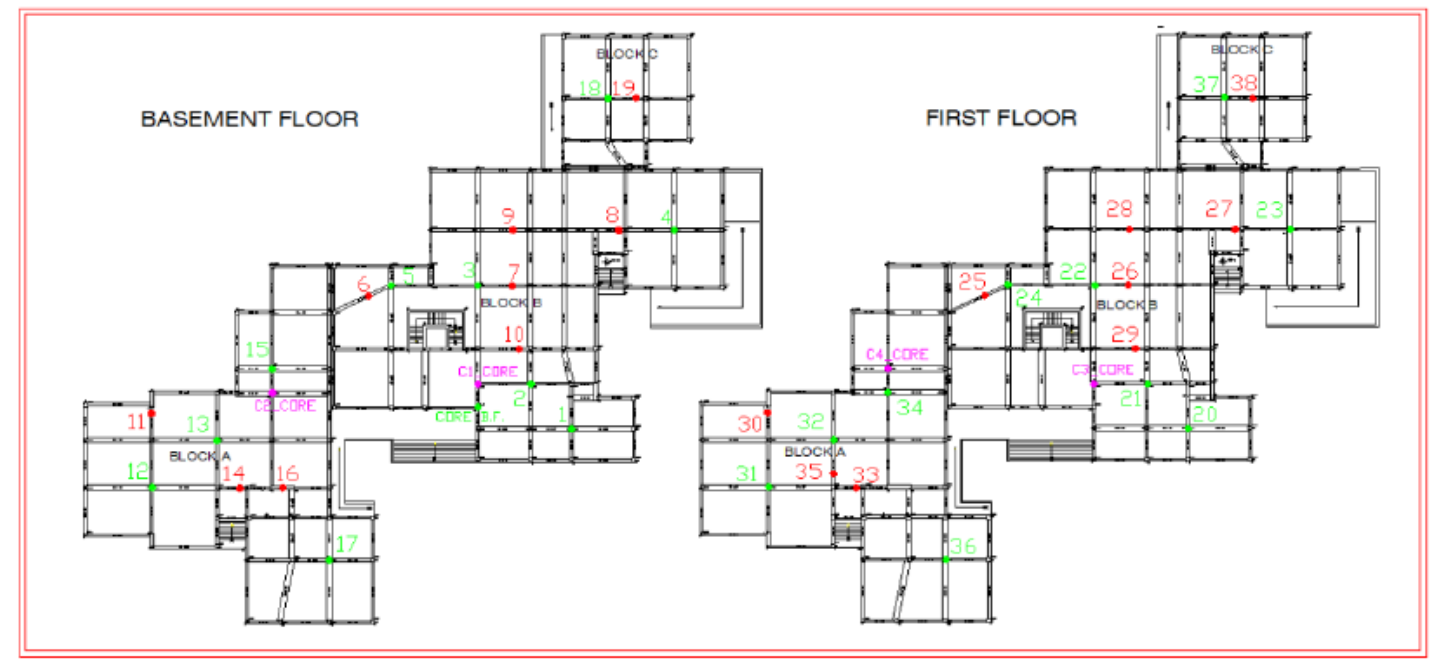

Figure 1 Scheme and location on the building plant of the tests. Colors code: green, pillars; red, beams; magenta, cores.

\section{RESULTS}

\subsection{Destructive Testing}

Compressive test on the cores furnishes the core resistance values, $\mathrm{f}_{\mathrm{c}}$. In order to get the corresponding cubic resistance, several correlation formulas are present in the literature. A first proposal can be found in the British Standard [37] that is:

$$
R_{C B S}=\left(\frac{f_{c} \times k_{1}}{1.5+\frac{d}{h}}\right)
$$

where the value, $\mathrm{R}_{\mathrm{c}}$, depends on diameter/height the ratio, $\mathrm{d} / \mathrm{h}$, and by the non-dimensional parameter $k_{1}$ which takes into account the layout of the core's axis with respect to the casting gravity direction. Among the others we can recall that for cores axis orthogonal to cast direction $k_{1}=2.5$ and for parallel direction $k_{1}=2.3$. A further relationship is proposed by the Concrete Society [38]:

$$
R_{C C S}=\left(\frac{1.25 f_{c} \times k_{2}}{1.5+\frac{d}{h}}\right)
$$

in which the factor $k_{2}$ always depends on the picking direction and assumes value 2.0 and 1.84 respectively in the two cases mentioned above. The "Linee Guida" of the Italian Consiglio Superiore dei Lavori Pubblici [39], recommend that the resistance obtained through core drilling is not less than 0.85 times the cylindrical strength of the concrete in situ. Furthermore, it is established that the strength of cores with unitary ratio can be assimilated to those of cubic specimens, while, when the ratio $h / d=2.0$, the cubic resistance, $R_{c}$, is equal to $1.25 f_{c}$. Then the following relationship can be derived from the Linee Guida:

$$
R_{c L G}=\frac{f_{c}}{0.85}\left[1+0.25\left(\frac{h}{d}-1\right)\right]
$$


The use of Destructive and Non-Destructive Testing in Concrete Strength Assessment for a School Building

The measured values of $f_{c}$ obtained by the ND test on cores are reported in the following table, Table 1.

Table 1 Core data: label, diameter, height and stress resistance.

\begin{tabular}{|c|c|c|c|c|c|c|}
\hline $\mathbf{n .}$ & $\boldsymbol{d}[\mathbf{m m}]$ & $\boldsymbol{h}[\mathbf{m m}]$ & $\boldsymbol{f}_{\boldsymbol{c}}[\mathbf{M P a}]$ & $\boldsymbol{R}_{\boldsymbol{c B S}}[\mathbf{M P a}]$ & $\boldsymbol{R}_{\boldsymbol{c} \text { CS }}[\mathbf{M P a}]$ & $\boldsymbol{R}_{\boldsymbol{c L G}}[\mathbf{M P a}]$ \\
\hline $\mathrm{C} 1$ & 104 & 207 & 34.9 & 43.57 & 43.57 & 51.23 \\
\hline $\mathrm{C} 2$ & 103 & 208 & 35.8 & 44.92 & 44.92 & 52.92 \\
\hline $\mathrm{C} 3$ & 103 & 209 & 16.9 & 21.16 & 21.16 & 24.95 \\
\hline $\mathrm{C} 4$ & 103 & 209 & 16.7 & 20.90 & 20.90 & 24.65 \\
\hline
\end{tabular}

Figure 2 shows the values of the compressive cubic strength calculated using the relationships above mentioned and the core resistances and geometry reported in Table 1 . The resistance values obtained from the formulas of the British Standard and of the Concrete Society are practically the same for all the cores pulled out, while the expression suggested by Linee Guida of the Consiglio Superiore dei Lavori Pubblici overestimates the resistance value, for C1 and C2. Also, the standard deviation evaluated for all the proposed relationships assumes higher values for the cores signed with the number $\mathrm{C} 1$ and $\mathrm{C} 2$ at the basement. Furthermore, all formulas give the highest resistance values for the cores extracted at the basement. The value of the compressive cubic strength of pillar 25 decreases of almost one half moving from the bottom to the top along the storeys. The Figure 3 shows the average resistance values calculated for all the formulas together with the respective standard deviation. It can be seen that the formulas are non-conservative due to the high values assumed by the standard deviation.

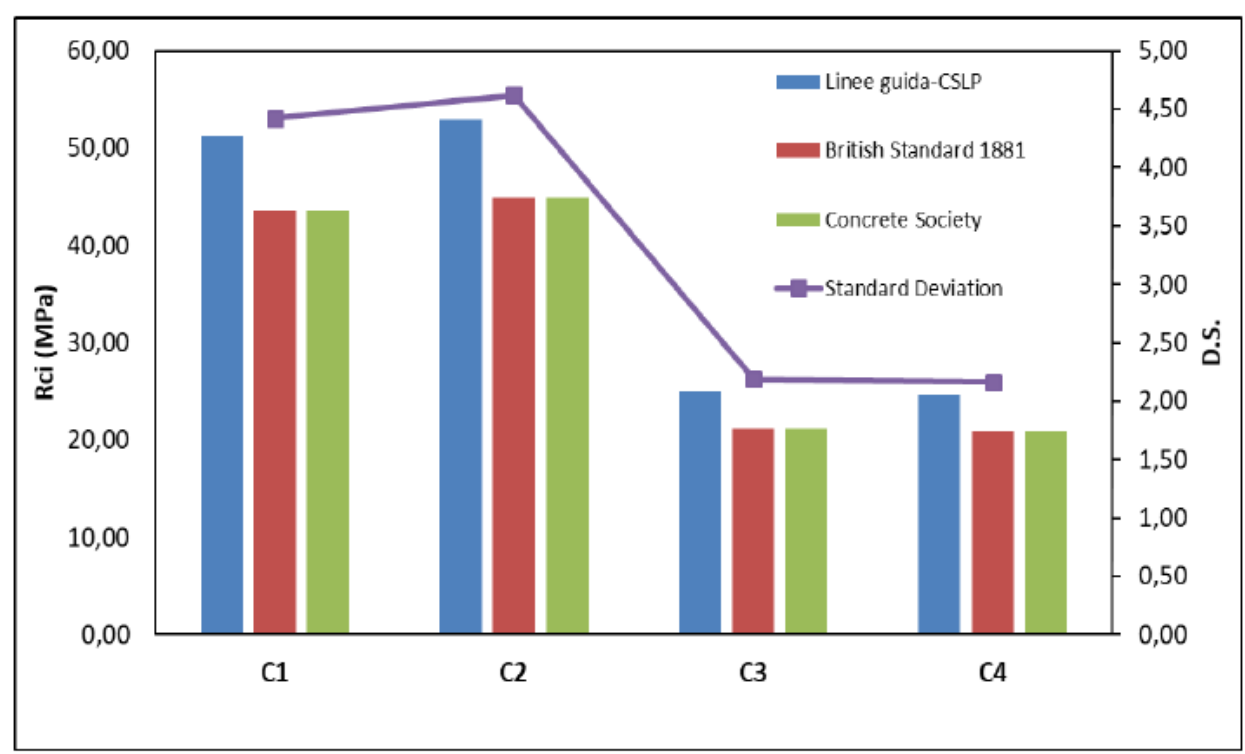

Figure 2 Compressive cubic strength values of cores calculated with the equations proposed in the literature. 


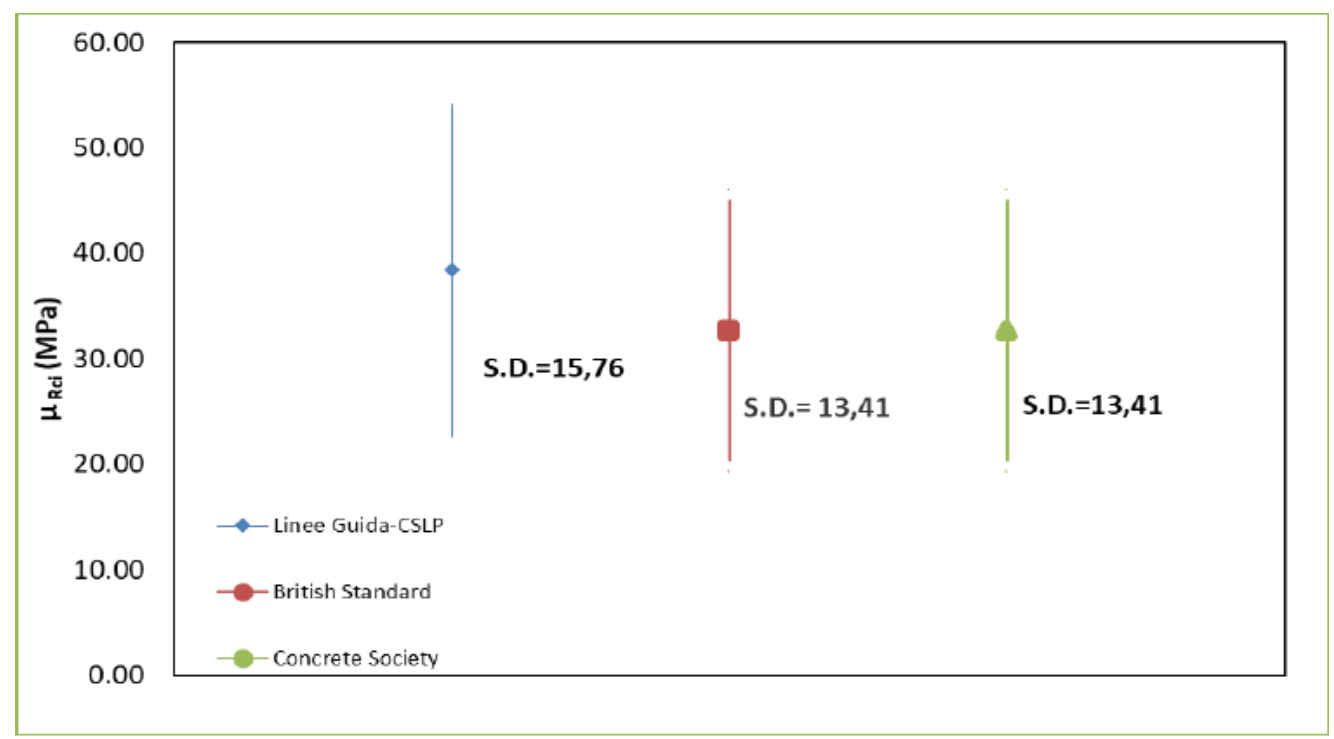

Figure 3 Average and standard deviation values of Rci, calculated with the equations proposed in the literature.

\subsection{Non-destructive tests - Sonreb method}

The compressive cubic equivalent strength of concrete, $\mathrm{R}_{\mathrm{c}}$, was derived from empirical correlations proposed in the literature as a function of the surface rebound index, Ir, and of the ultrasonic speed, $\mathrm{V}$ evaluated in the 40 measurement points. Figure 4 shows the $\mathrm{R}_{\mathrm{c}}$ values for the pillars at the basement using the expressions (2-5). It is possible to note that the Sonreb relations used give almost equal $R_{c}$ values for all the pillars with low standard deviation values as shown in the graph. The $R_{c}$ values are comparable also for the beams at the same floor, with values of the standard deviation lower than the pillars (Figure 5). The same result has been reached for the structural elements of beams-pillars at the first floor with almost coincident values of the standard deviation. Figure 6 shows, for each floor, the averages of the $R_{c}$ values evaluated with the Sonreb relationships (2-5) for the beams and pillars elements. From last results it is evident, as for the cores, that there is a difference between the values relating to the pillars at the basement and those at the first floor; indeed the $\mathrm{R}_{\mathrm{c}}$ are higher at the basement with a percentage difference of about $55 \%$ respect to the first floor. The $R_{c}$ values for the beams on the two floors are comparable but however lower than those of the pillars at the basement. In Table 2 the corresponding Standard deviation values are shown as well. It is evident that, for all floor, the $R_{c}$ values are variable from pillar to pillar and from beam to beam as shown by high standard deviation values. The least value of standard deviation results for the beams at first floor that present a rather singular behaviour. It can be noticed that the basement concrete is more resistant than the first floor one. Moreover vertical members are more resistant than horizontal, say beams. The reason of the differences can be ascribed to the difference of sedimentation of aggregates with reference to pillars compared to beams. Finally the differences between the two storeys have to be investigated with more accuracy since it seems to depend by more definitive difference on concrete composition. 
The use of Destructive and Non-Destructive Testing in Concrete Strength Assessment for a School Building

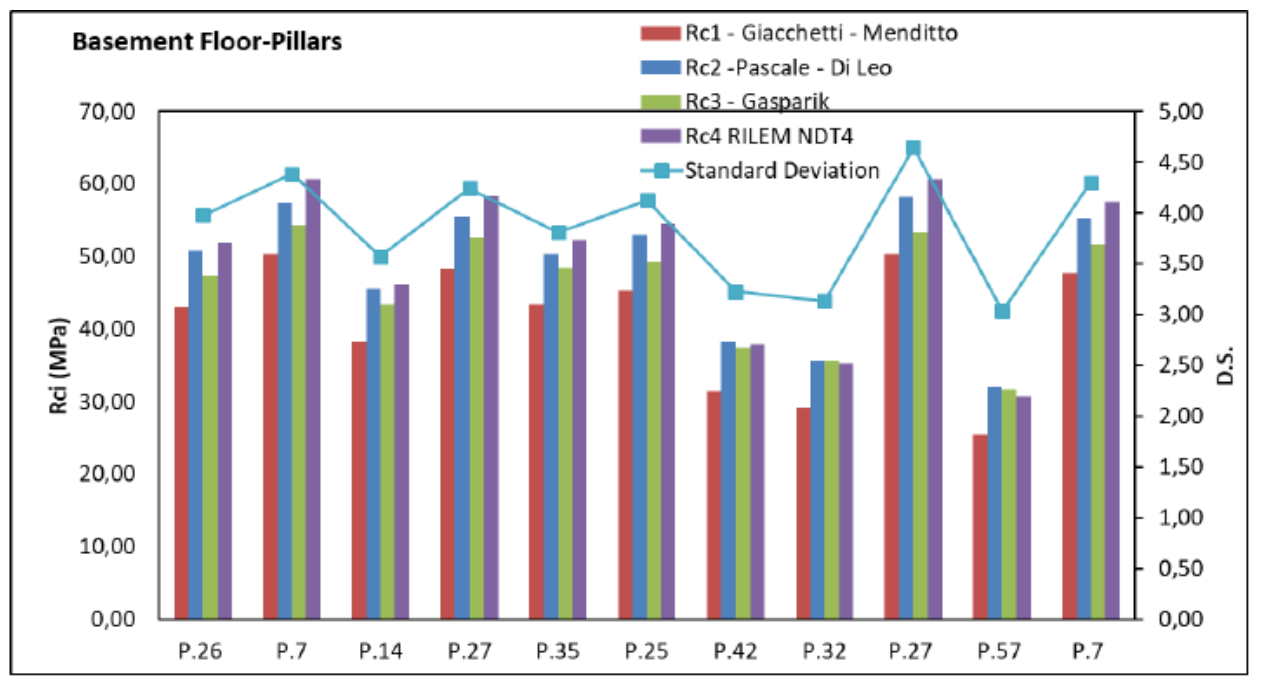

Figure 4 Compressive cubic strength, Rc, values of pillars calculated with the Sonreb relations and their standard deviation values.

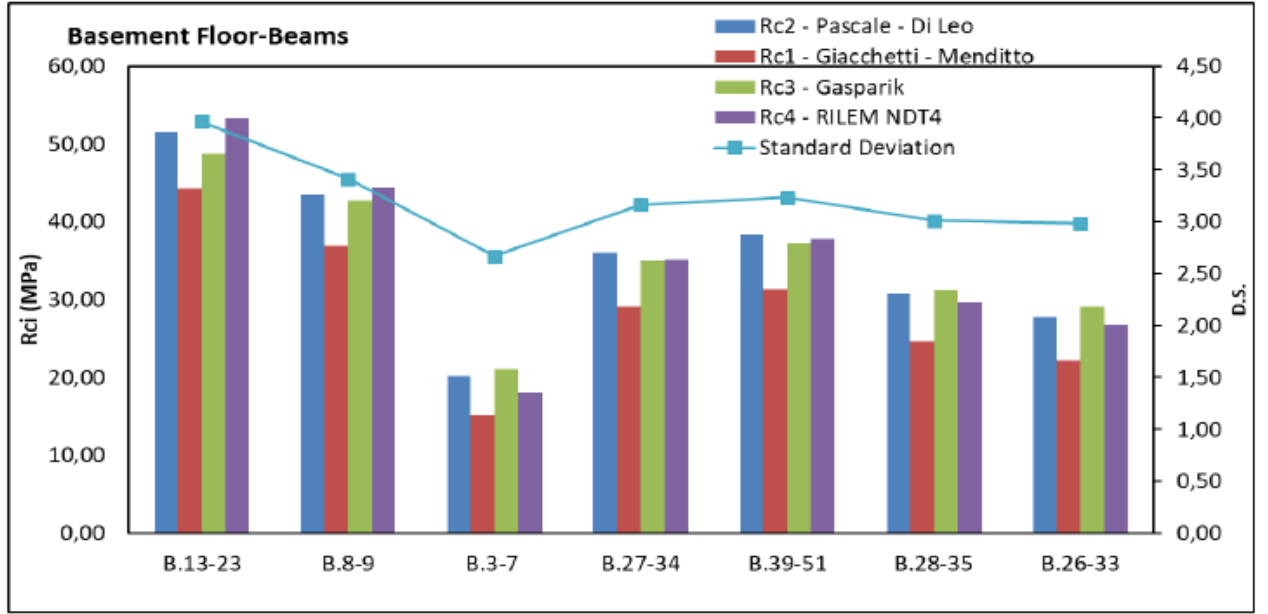

Figure 5 Compressive cubic strength, Rc, values of beams calculated with the Sonreb relations and their standard deviation values.

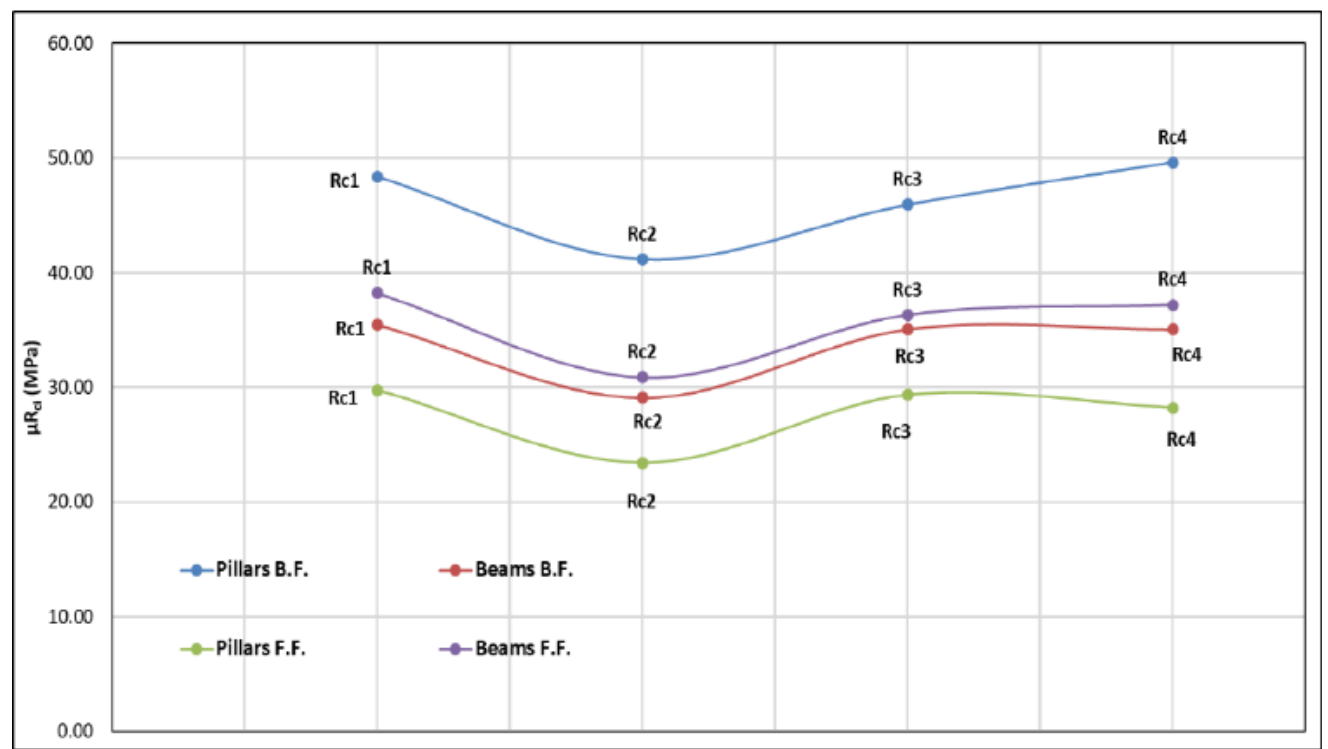

Figure 6 Average values of beams and pillars cubic resistance, Rci, calculated with the Sonreb relations. 
Table 2 Standard Deviation values of beams and pillars cubic resistance, Rci, calculated from the Sonreb relations.

\begin{tabular}{|c|c|c|c|c|}
\hline \multicolumn{5}{|c|}{ Standard Deviation } \\
\hline & Rc1 & Rc2 & Rc3 & Rc4 \\
\hline Pillar B.F. & 9.19 & 8.83 & 7.81 & 10.63 \\
\hline Pillar F.F. & 7.12 & 6.52 & 6.54 & 7.86 \\
\hline Beams B.F. & 10.39 & 9.64 & 9.10 & 11.61 \\
\hline Beams F.F. & 4.31 & 3.98 & 3.62 & 4.79 \\
\hline
\end{tabular}

\subsection{Proposed procedure based on core sampling and non-destructive investigations}

Figure 7 shows the concrete compressive strengths in situ, $\mathrm{f}_{\mathrm{c}}$, obtained by crushing the cores and the results of the non-destructive tests performed at the measurement points where the cores themselves were extracted. As it can be seen from the Figure 7, the surface rebound index and the ultrasonic velocity increase at the increasing of the compressive cylindrical strength, $\mathrm{f}_{\mathrm{c}}$, with a good correlation, $\mathrm{R}^{2}$, equal respectively to $\mathrm{R}^{2}=0.984$ and to $\mathrm{R}^{2}=0.868$. The surface rebound index and the ultrasonic velocity compared to each other show a good correlation with an $\mathrm{R}^{2}$ value of 0.939 [40].
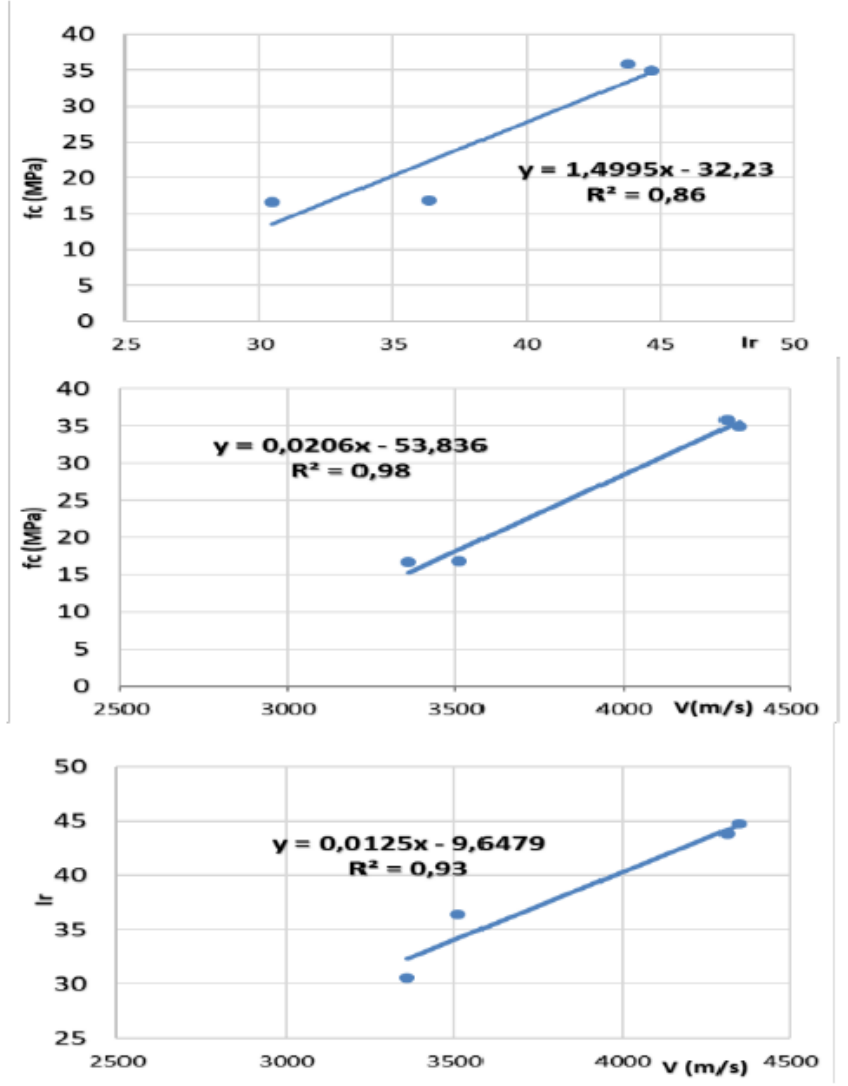

Figure 7 Concrete core results of destructive and non-destructive tests.

Figure 8 shows compressive strength values of the cores applying the Sonreb relations (25) and the British Standard. As it is visible, the resistance values are almost coincident with standard deviation values decreasing by moving upstairs. 
The use of Destructive and Non-Destructive Testing in Concrete Strength Assessment for a School Building

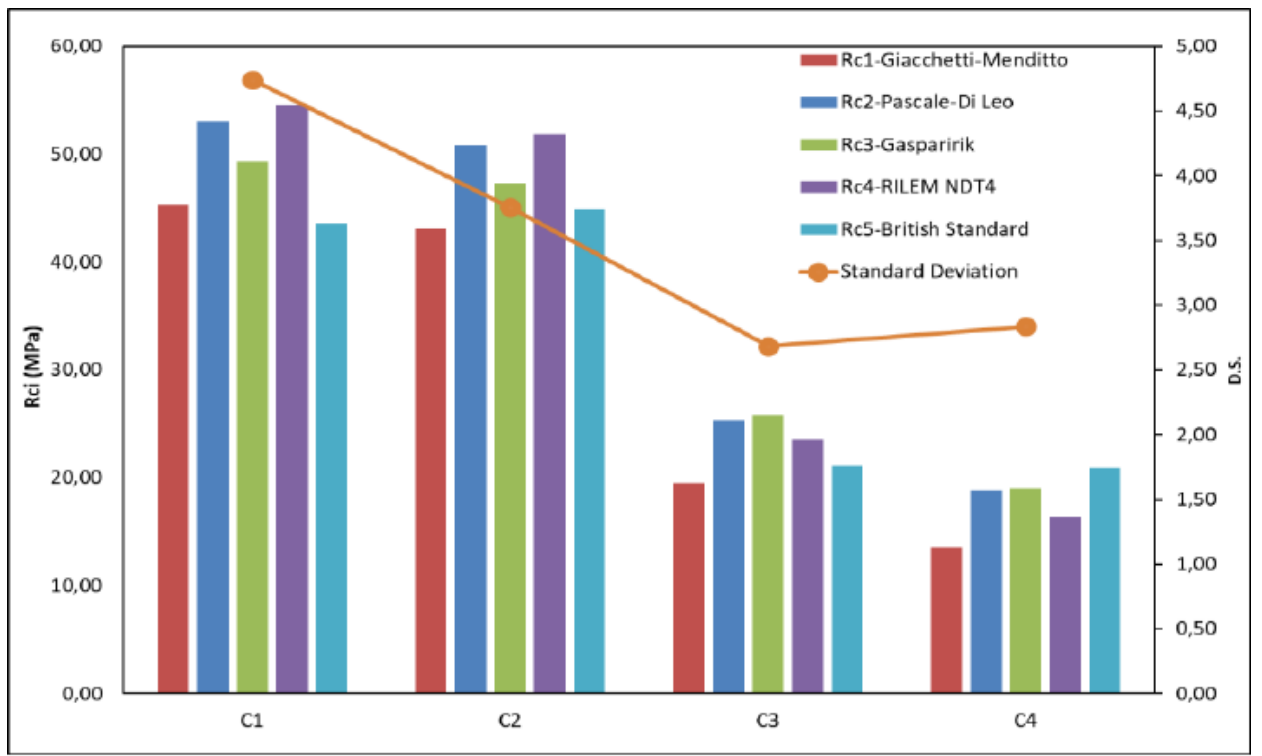

Figure 8 Compressive cubic strength, Rc, values of cores calculated with the Sonreb relations and British Standard and their standard deviation values.

Whether one get the correlation between the values of Ir, V and the resistance cores, $f_{c}$, it was possible to obtain a correlation for the case study that best fits three parameters using a relation of the kind of $R_{c}=a \cdot l^{b} V^{c}$. The values $a, b$ and $c$ are constants and were determined by the least square's method. In the case study, the following correlation curve was derived by an optimization procedure where best-fit curve has been obtained using Mathematica ${ }^{\circledR}$ software:

$$
R_{c, \text { corr }}=3.1 \times 10^{-5} \mathrm{Ir}^{1.8468} \mathrm{~V}^{0.8516}
$$

in which concrete cubic compressive strength, $\mathrm{R}_{\mathrm{c}}$, is expressed in MPa while the ultrasonic velocity in $\mathrm{m} / \mathrm{s}$ with the mean error estimated in $\mathrm{e}=0.065$. Figure 9 shows the comparison between the compressive strengths, $f_{c}$, obtained from the crushing of the cores with the respective values, $R_{c, \text { corr }}$, calculated through the correlation (9) from the Ir and V measured on the structural element where the cores have been extracted. The values are a little above the line at $45^{\circ}$ for the $\mathrm{C} 1-\mathrm{C} 2-\mathrm{C} 3$ cores while for the $\mathrm{C} 4$ core are coincident.

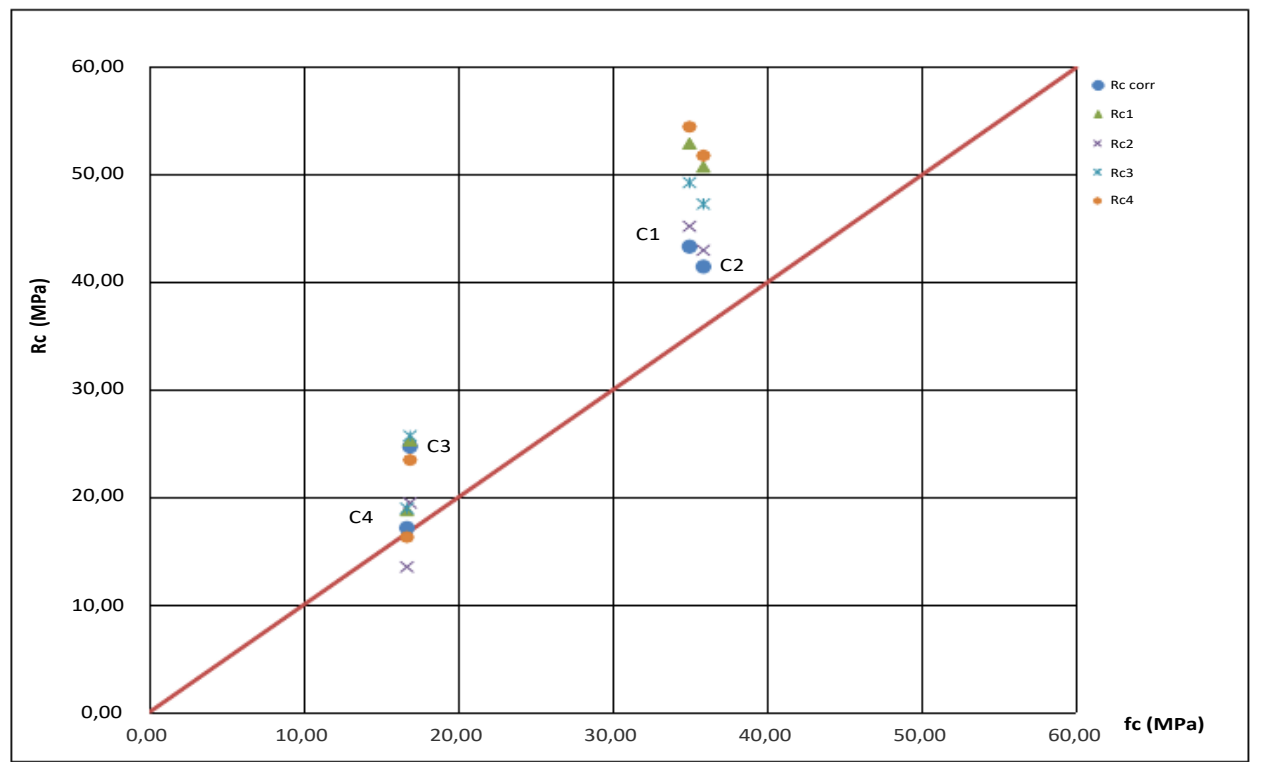

Figure 9 Comparison between core resistance values, fc, and cubic resistance values, Rc, Sonreb, Rc,corr. 
In Figure 9, the relation (9) has been also compared with the relationships (2-5). Figure 10 shows, for the pillars of both floors, the $\mathrm{R}_{\mathrm{c}}$ values estimated with the Sonreb relationship and with the equation (9). As it can be seen for both floors, the relations (2-5) give values higher than those obtained by (9).

The standard deviation of the formulas (2-5) valuated respect to that obtained by means of relation (9) is shown in Figure 11. At the basement pillars, the value of the deviation is between a minimum of 0.43 and a maximum of 5.53, while at the first floor between 0.86 and 2.54. Similarly, for the beams at the basement and the first floor the values of the $R_{c}$ are shown in Figure 12.

The standard deviation is represented in Figure 13 varying between a minimum value of 1.11 and a maximum of 3.10 at the basement while at the first floor between a value of 0.77 and a value of 4.41 .

Then for all the cases examined, the formulations available in literature for estimating the concrete cubic strength, $R_{c}$, provide rather variable results and are not entirely consistent since they are obtained to different purposes.

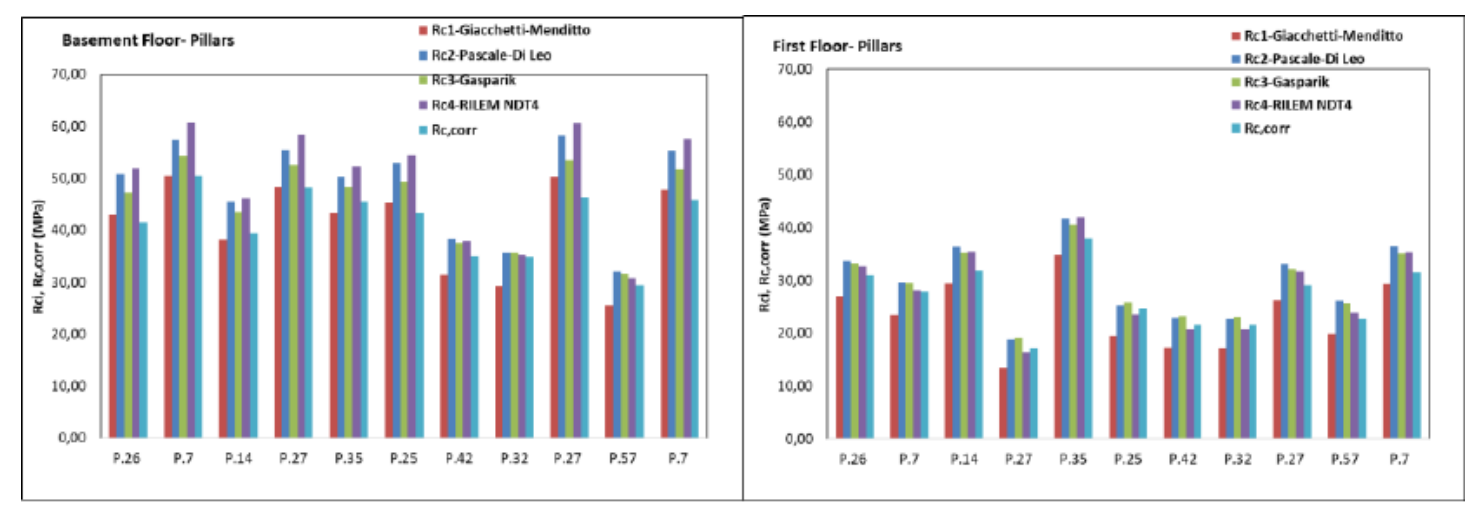

Figure 10 Comparison between the Rc values of pillars evaluated with the Sonreb relations and Rc,corr's.

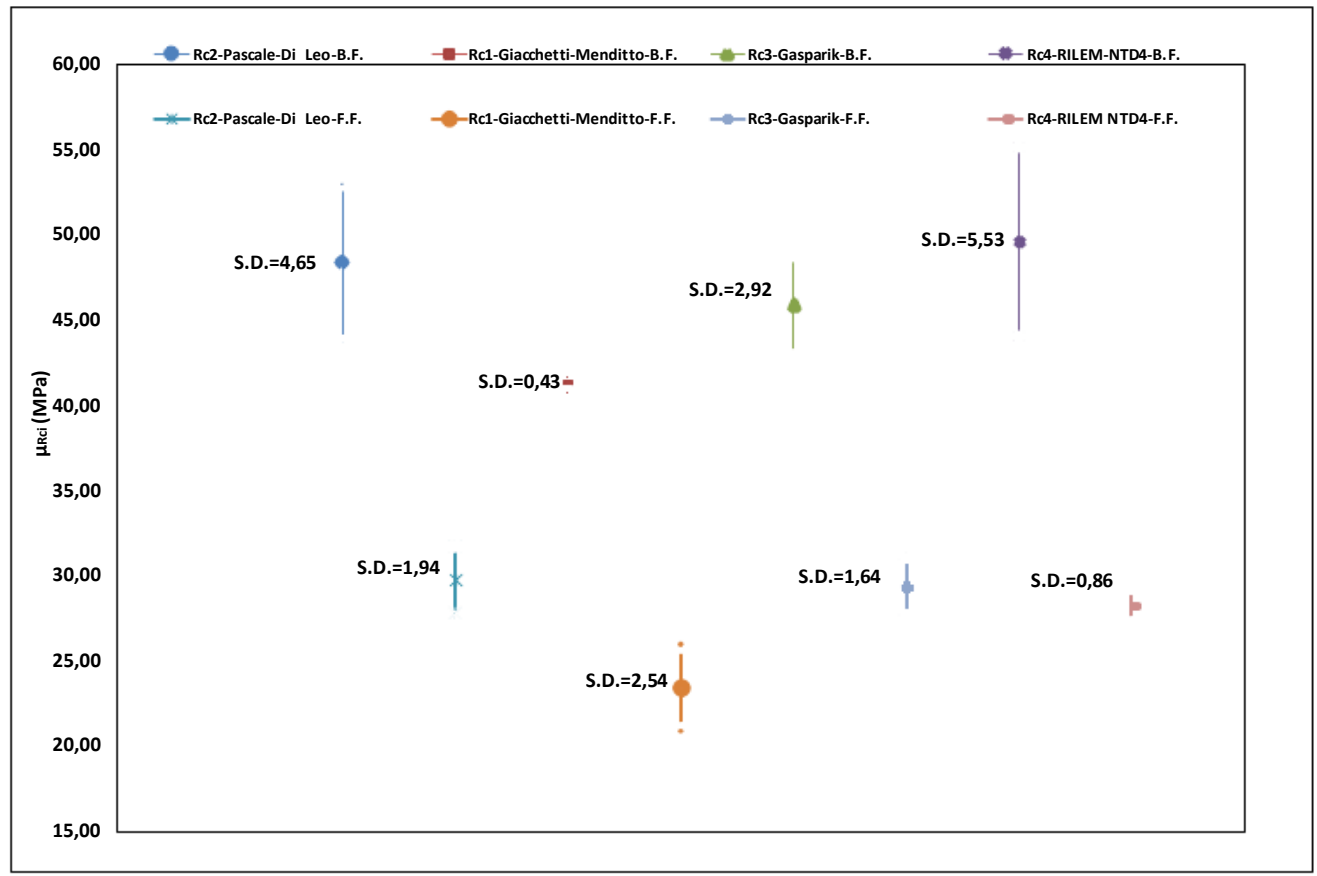

Figure 11 Average and standard deviation values of pillars resistance, Rci, calculated with Sonreb relations. 


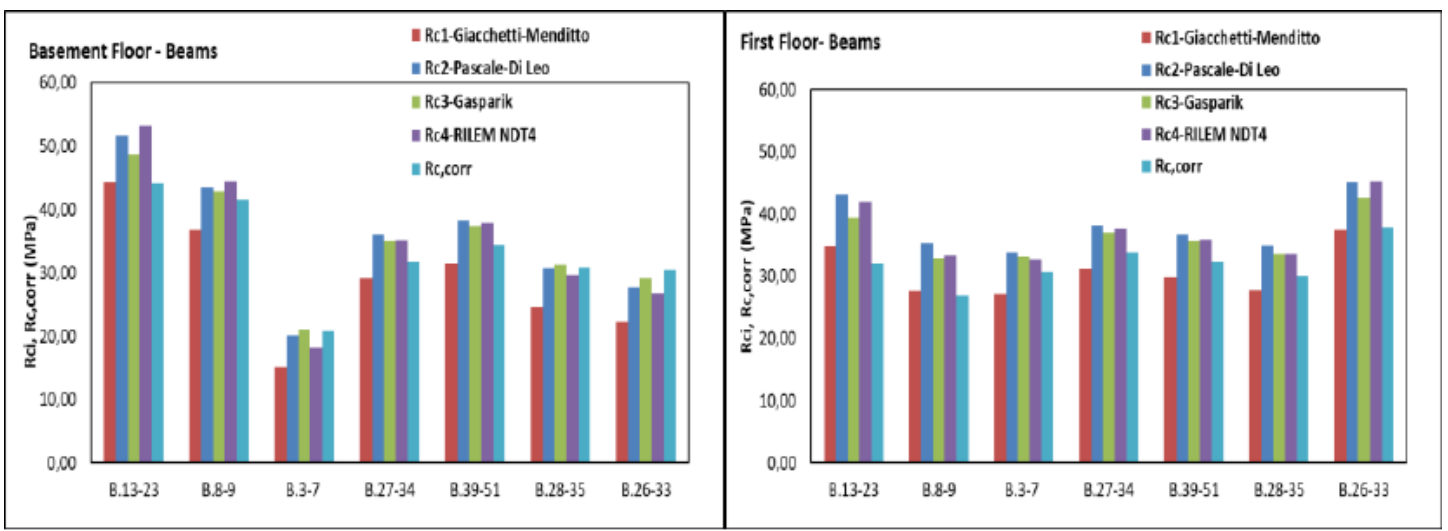

Figure 12 Comparison between the Rc values of beams evaluated with the Sonreb relations and Rc,corr's.

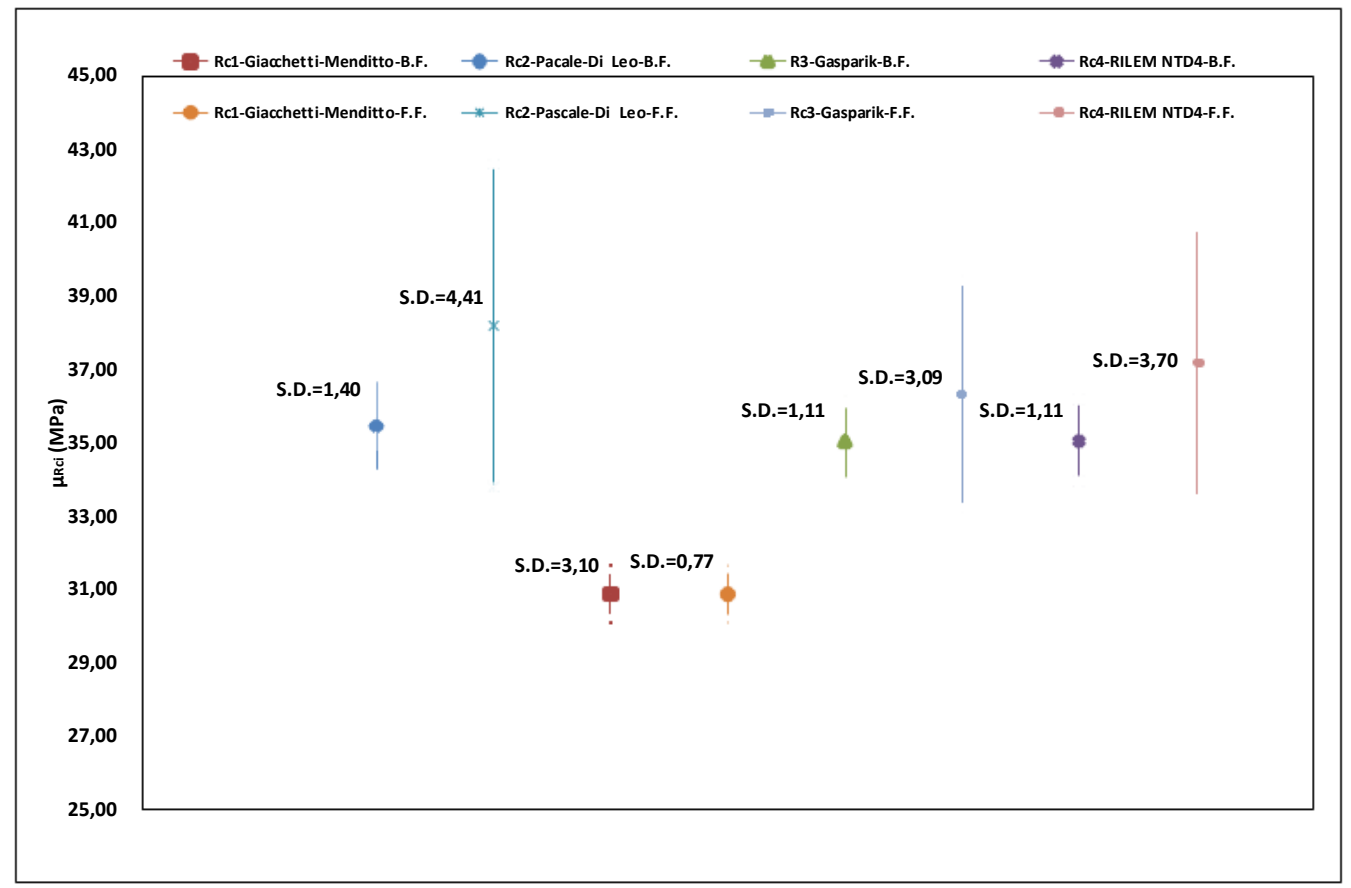

Figure 13 Average and standard deviation values of beams resistance, Rci, calculated with Sonreb relations.

\section{CONCLUSION}

In the present paper the results of experimental investigations carried out on concrete conglomerate samples of a school building has been shown. The main non-destructive (surface rebound index method, ultrasonic speed method, combined Sonreb method) and destructive (coring) tests are summarized and examined to estimate the concrete strength. Destructive methods, DT, provide locally reliable results but, given their limited number, they are not very representative. The non-destructive methods, NDT, provide absolutely unreliable results but, due to their greater distribution, are able to better reproduce the variability of the concrete properties in situ. Then a procedure has been highlighted to estimate the concrete strength in situ by destructive and non-destructive tests coupling. Then the expression obtained through the calibration procedure of the values of non-destructive tests with those provided by the core drills allowed to estimate the average values of the compressive cubic strength of the concrete. Moreover, it is highlighted how this result was achieved with a very limited core number (core number is equal to 4 corresponding to the $10 \%$ of the non-destructive test number) provided 
that they are extracted in randomly chosen points and that there was a proportionality link with the resistances obtained from non-destructive tests. The experimental tests described in the present work has shown a consistent variability of the measured values of the single elements, beams and pillars, at the first floor and at the basement and between floor and floor. In particular, a more marked variability of the resistance values of the cores extracted between the two storeys has been confirmed. It emerges from this evidence that heterogeneity of concrete cast plays a relevant role on the distribution of resistance on the structure. It is very important, hence, to design the position and the number of DT, namely cores, in order to get sufficient data for correlation on portions of the structure supposed to be almost homogeneous. The described experiment has shown that the two storeys of the building have different average strength so that only two cores for each floor could be not sufficient.

However, the reported results seem to give accurate qualitative information on the actual distribution and magnitude of the resistance of the concrete and can be used as a basis for more accurate investigations. For all the examined cases, the formulations available in literature for estimating the concrete cubic strength provide rather variable results and are not entirely consistent, since they are obtained to different purposes, to proposed relation. Therefore, the useful recommendation derived from the present work is to conduct a wide campaign of nondestructive investigations in order to identify the concrete characteristics of the structural elements. From of the results of the NDT, the presence of one or more consistent areas can be identified and, therefore, to produce the test program planning in order to establish the number and location of the core samples in the structure. Furthermore, the possibility of identifying any abnormal values of the strengths provided by the cores using the NDT results should not be underestimated. Finally, it should be noted that the method illustrated in [5], linked with the technical standards [1] applied to present paper, leads to a good estimation of the average values of concrete compressive cubic strength to be adopted, confirming what has already emerged in [41]. In conclusion, the paper deals with the exemplification of an actual case of study where the formulation for SonReb correlations have been used. It is in the opinion of the authors that the correlation in literature are useful and have to be used, however one can set up a self-made best fit of the cores data calculating the best parameters of the equation (1). Important is to check that the result does not differ too much from literature to prevent macroscopic mistakes on the interpretation of experimental data.

\section{REFERENCES}

[1] OPCM 3274. Primi elementi in materia di criteri generali per la classificazione sismica del territorio nazionale e di normative tecniche per le costruzioni in zona sismica; Ordinanza del Presidente del Consiglio dei Ministri (Gruppo di Lavoro istituito dal Dipartimento di Protezione Civile), marzo 2003 (revisione del 12/1/2005).

[2] Eurocode 8. Design of structures for earthquake resistance - Part 3: Assessment and retrofitting of buildings (draft n. 6); CEN, 2004.

[3] Vecchio, C.D.; Ludovico, M.D.; Prota, A.; Cosenza, E.; Manfredi, G. Correlation of in-situ material characterization tests and experimental performances of RC members. Lecture Notes in Civil Engineering 2016,10, 454-466.

[4] Park, G.K., Yim, H.J. Evaluation of Fire-Damaged Concrete: An Experimental Analysis based on Destructive and Nondestructive Methods, Int. Jour. Concrete Structures and Materials, 2017, 11, (3),447-457.

[5] Kabir, M.I., Samali, V., Sharestha, R., Pull-out Strengths of GFRP-Concrete Bond Exposed to Applied Environmental Conditions, Int. Jour. Concrete Structures and Materials, 2017, $11,(1), 68-84$. 
The use of Destructive and Non-Destructive Testing in Concrete Strength Assessment for a School Building

[6] Mohammed, B.S.; Adamu, M. Non-destructive evaluation of nano silica-modified rollercompacted rubbercrete using combined SonReb and response surface methodology. Road Materials and Pavement Design, 2019, 20 (4), 815-835.

[7] Masi, A. La stima della resistenza del calcestruzzo in situ mediante prove distruttive e non distruttive. AIPnD 2005, 1.

[8] Shih, Y. F.; Wang, Y. R.; Lin, K. L.; Chen, C.-W. Improving non-destructive concrete strength tests using support vector machines. Materials 2015, 8 (10), pp. 7169-7178.

[9] Nobile, L. Prediction of concrete compressive strength by combined non-destructive methods. Meccanica 2015, 50 (2), 411-417.

[10] Faella, C; Martinelli, E.; Salerno, N. Alcune considerazioni sui metodi non distruttivi per la determinazione delle proprietà meccaniche del calcestruzzo. Proceedings of the XVII Congress of C.T.E, Italia, 5-6-7-8 novembre 2009

[11] Pucinotti, R. The use of multiple combined non-destructive testing in the concrete strength assessment: applications on laboratory specimens. Proceedings of the HSNDT, 2014.

[12] Breysse, D.; Balayssac, J.P.; Biondi, S.; Borosnyói, A.; Candigliota, E.; Chiauzzi, L.; Garnier, V.; Grantham, M.; Gunes, O.; Luprano, V.; Masi, A.; Pfister, V.; Sbartai, Z.M.; Szilagyi, K.; Fontan, M. Non-destructive assessment of in situ concrete strength: comparison of approaches through an international benchmark. Materials and Structures/Materiaux et Constructions 2017, 50(2), 133.

[13] Malhotra, V. M.; Carino, N. J. CRC Handbook on Nondestructive Testing of Concrete, CRC Press, 1991.

[14] Braga, F.; Dolce, M.; Masi, A.; Nigro, D. Valutazione delle caratteristiche meccaniche dei calcestruzzi di bassa resistenza mediante prove non distruttive. iiC 1992, 3, 201-208.

[15] Pucinotti, R. L'utilizzo del Metodo Windsor nella Valutazione della Resistenza Meccanica del Conglomerato Cementizio. Proceedings of Convegno Internazionale Crolli e Affidabilità delle Strutture Civili, Università degli Studi di Messina, Aprile 2006.

[16] Pucinotti, R.; De Lorenzo, R. A. Nondestructive in Situ Testing for the Seismic Damageability Assessment of "Ancient" R/C Structures. Proceedings of the 3rd International Conference on NDT, Chania, Greece, 2003, 189-194.

[17] De Berardinis, P.; Bartolomucci,C.; Capannolo,L.; De Vita, M.;Laurini, E.; Marchionni, C. Marchionni Instruments for Assessing Historical Built Environments in Emergency Contexts: Non-Destructive Techniques for Sustainable Recovery. Buildings 2018, 8 .

[18] Concu, G.; Trulli, N. Concrete Defects Sizing by Means of Ultrasonic Velocity Maps. Buildings 2018, 8.

[19] Maierhofer, C.; Reinhardt, H.W.; Dobmann, G. Non-Destructive Evaluation of Reinforced Concrete Structures: Non-Destructive Testing Methods; Woodhead Publishing: Cambridge, UK, 2010; ISBN 9781845699604.

[20] Fiore, A.; Porco, F.; Uva, G.; Mezzina, M. On the dispersion of data collected by in situ diagnostic of the existing concrete. Construction and Building Materials 2013, 47, 208-217.

[21] OPCM 3431/05. Norme tecniche per il progetto, la valutazione e l'adeguamento sismico degli edifici - Ulteriori modifiche ed integrazioni all'OPCM n ${ }^{\circ} 3274$ del 20/03/03, All. 2, G. U. n. 107 del 10/05/2005.

[22] UNI EN 1998-3. Eurocodice 8, parte 3: Assessment and retrofitting of exisisting buildings, 2005.

[23] McCann, D.M.; Forde, M.C. Review of NDT methods in the assessment of concrete and masonry structures. Ndt E Int. 2001, 34, 71-84.

[24] Berke, M. Non-destructive material testing with ultrasonics. Introduction to the basic principles. NDT.net 2000, 5, 9 . 
[25] UNI EN 12504-2. Testing concrete in structures - Part 2: Non-destructive testing Determination of rebound number, 2012.

[26] ASTM C 805. Standard Test Method for rebound Number of Hardened Concrete, Philadelphia, Pennsylvania, 1985.

[27] UNI EN 12504-4. Testing concrete - Part 4: Determination of ultrasonic pulse velocity, 2005.

[28] Masi, A.; Vona, M.; Nigro, D.; Ferrini, M. Indagini sperimentali per la stima della resistenza del calcestruzzo in-situ basata su metodi distruttivi e non distruttivi" Proceeding of Convegno ReLuis Valutazione e riduzione della vulnerabilità sismica di edifici esistenti in c.a., Roma, Italy, 29-30 Maggio 2008.

[29] Di Leo, A.; Pascale, G. Prove non distruttive sulle costruzioni in c.a. AIPnD 1994, 4.

[30] Gasparik, J. Prove non distruttive nell' edilizia. AIPnD, 1992.

[31] RILEM NDT 4. Recommendations for in situ concrete strength determination by combined non-destructive methods, Compendium of RILEN Technical Recommendations, E\&FN Spon, London, 1993.

[32] Masi, A.; Chiauzzi L. An experimental study on the within-member variability of in situ concrete strength in RC building structures. Constr Buil Mater 2013, 47, 951-961.

[33] UNI EN 12390-1. Testing hardened concrete - Part 1: Shape, dimensions and other requirements for specimens and moulds, 2000.

[34] UNI EN 12504-1. Testing concrete in structures - Part 1: Cored specimens - Taking, examining and testing in compression, 2009.

[35] D.M. 9/1/96 - Ministero LL.PP. Norme tecniche per l'esecuzione delle opere in cemento armato e precompresso, 1996.

[36] Eurocode 2: Design of concrete structures - Part 1-1: General rules and rules for buildings (final draft), CEN, December 2003, prEN 1992-1-1, Brussels.

[37] British Standard 1881. Testing Concrete, part 120 - Methods for determination of the compressive strength of concrete cores, 1983.

[38] Concrete Society. Concrete core Testing for Strength; Technical Report n. 11, London, 1987.

[39] Consiglio Superiore Dei Lavori Pubblici - Servizio Tecnico Centrale. Linee guida per la messa in opera del cls strutturale, 2008.

[40] Kovler, K.; Wang, F.; Muravin, B. Testing of concrete by rebound method: Leeb versus Schmidt hammers Material and Structures 2018, 51 (5)

[41] Dolce, M.; Masi, A.; Ferrini, M. Estimation of the actual in-place concrete strength in assessing existing RC structures. Proceedings of The Second International fib Congress, Naples, Italy, June 5-8, 2006.

[42] Anthony N. Ede, Oluwarotimi M. Olofinnade, Olatokunbo M. Ofuyatan, Opeyemi Joshua, Oluwadamilola Aremu, Use of Non-Destructive Tests to Avert the Risk of Building Collapse. International Journal of Civil Engineering and Technology, 9(7), 2018, pp. 20282035.

[43] S V Ranganayakulu, J Narsaiah, B Samrat Goud, S Ravi and K Sudhakar. Quality Assurance of Structural Aluminum Aerospace Materials through Non-Destructive Testing Techniques. International Journal of Mechanical Engineering and Technology, 8(1), 2017, pp. 110-119. 